\title{
ANALISIS DAN PERANCANGAN SISTEM INFORMASI INVENTORY PADA PT.PGAS TELEKOMUNIKASI NUSANTARA PALEMBANG
}

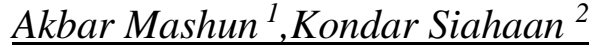 \\ Program Studi Magister Sistem Informasi, STIKOM Dinamika Bangsa, Jambi \\ Jl. Jendral Sudirman, Kec. The Hok, (0741) 35095 \\ Email: akbar.mashun@gmail.com ${ }^{1}$, kondarsn@yahoo.com $^{2}$
}

\begin{abstract}
Abstrak
Sistem Inventory merupakan suatu sistem untuk mengetahui persediaan stok barang pada suatu tempat. Sistem inventory sudah banyak digunakan atau dikembangkan pada suatu tempat dengan berbagai macam teknologi dan sistem. Permasalahan PT.PGAS Telekomunikasi Nusantara ini adalah belum tersedianya sistem inventory barang sehingga belum bisa mengontrol stok barang yang tersedia secara cepat. Oleh karena itu, penulis merancang Prototype aplikasi yang dapat menyajikan informasi data yang dibutuhkan secara cepat. Metode pengembangan sistem pada aplikasi ini menggunakan metode System Development Life Cycle (SDLC) dan Unified Modelling Languange (UML) sebagai alat permodelannya. Berdasarkan Konsep dan Perancangan, dapat disimpulkan telah dirancang Sistem Inventory pada PT.PGAS Telekomunikasi Nusantara Palembang untuk membantu admin, manager dan front desk sehingga dapat berinteraksi dengan aplikasi ini sesuai dengan informasi yang dibutuhkan melalui menu yang tersedia. Penelitian ini menghasilkan Prototype Aplikasi Inventory. Bertujuan agar perusahaan dapat melakukan pengembangan gudang dan persediaan barang secara online.
\end{abstract}

Kata kunci: Sistem informasi, Inventory, Prototype, SDLC

\begin{abstract}
Inventory system is a system to find inventory of goods in a place. The inventory system has been widely used or developed in a place with a variety of technologies and systems. The problem of PT. PGAS Telekomunikasi Nusantara is the unavailability of an inventory inventory system so that it cannot control the stock of goods that are available quickly. Therefore, the author designs an application Prototype that can present data information needed quickly. System development methods in this application use the system of the Development Life Cycle (SDLC) system and the Unified Modeling Language (UML) as a modeling tool. Based on the Concept and Design, it can be concluded that the Inventory System in PT. PGAS Telekomunikasi Nusantara Palembang has been designed to help the admin, manager and front desk so that they can interact with this application according to the information needed through the available menu. This research produces Inventory Application Prototype. Aims so that companies can do warehouse development and goods preparation online.
\end{abstract}

Keywords: Information system, inventory, prototype, SDLC

(C) 2019 Jurnal Magister Sistem Informasi.

\section{Pendahuluan}

PT. PGAS Telekomunikasi Nusantara (PGASCOM) merupakan anak perusahaan dari PT. Perusahaan Gas Negara (Persero) Tbk. PGASCOM telah berpengalaman sebagai penyedia jaringan telekomunikasi dan layanan ICT Solution. PGASCOM telah melayani beberapa operator telekomunikasi, content provider maupun NAP/ISP melalui penyediaan jaringan Fiber Optik (FO) domestik dan internasional. Pengembangan 
pasar internasional dilakukan melalui anak perusahaan Pgas Internasional Pte, Ltd yang berbasis di singapura dan pasar korporasi dilakukan melalui anak perusahaan Telemedia Dinamika Sarana (TDS).

Visi dari PT. PGAS Telekomunikasi Nusantara adalah menjadi penyedia solusi teknologi informasi dan komunikasi terkemuka di Indonesia. Adapun Misi dari PT. PGAS Telekomunikasi Nusantara adalah :

Mengembangkan bisnis telekomunikasi untuk memenuhi kebutuhan domestik dan internasional Menyediakan solusi teknologi informasi dan komunikasi untuk mendukung PGN Group dan industri energi.

PT. PGAS Telekomunikasi Nusantara menyediakan berbagai paket layanan konektivitas data untuk provider telekomunikasi dengan kapasitas besar dan berstandar kelas carrier yang lengkap bagi pasar global. Layanan PGASCOM dirancang demi menunjang keberlangsungan bisnis bagi para penyelenggara telekomunikasi, GSM Operator, Network Accer Provider (NAP) ataupun Internet Service Provider (ISP). Dengan semua layanan PT. PGAS Telekomunikasi Nusantara diatas untuk mencapai visi misi perusahaan, dibutuhkan penanganan pelayanan yang cepat dan akurat untuk memberikan respon positif untuk para pelanggan PT. PGAS Telekomunikasi Nusantara dan banyaknya layanan yang harus diselesaikan dengan cepat dan efisien berdampak juga dengan ketersediaan Spare part atau perangkat pendukung untuk membantu dalam pengerjaan layanan oleh karyawan PT. PGAS Telekomunikasi Nusantara ditangani secara cepat dan akurat tanpa menunggu informasi apakah invetory diperusahaan masih tersedia atau tidak. Hal ini menjadi momok bagi perusahaan yang bekerja dibidang layanan, sehingga saat instalasi ataupun troubleshoot layanan yang bermasalah mendapati stok barang digudang tidak mencukupi atau kosong. PT. PGAS Telekomunikasi Nusantara Palembang Saat ini menggunakan sistem spreetsheet yang masih memiliki banyak kekurangan dan kelemahan seperti memerlukan waktu yang cukup lama untuk pengiriman surat serah terima barang, penyusunan laporan data persediaan barang dan pemesanan barang, yang masih manual menyebabkan kinerja perusahaan menjadi terhambat dan belum mampu menunjang segala kebutuhan yang diinginkan perusahaan.

\section{Tinjauan Pustaka/Penelitian Sebelumnya}

Untuk mengatasi permasalahan persediaan barang di PT.PGAS Telekomunikasi nusantara Palembang dapat dilakukan dengan memanfaatkan sistem informasi inventori yaitu sistem persediaan barang barang spare-part yang berbasis komputer yang dapat menyajikan informasi barang secara cepat, tepat dan akurat. Oleh karena itu perlu dilakukan pengembangan sistem informasi inventory berbasis komputer yang diharapkan dapat membantu mengatasi masalah persediaan barang digudang, khususnya spare-part digudang PT.Pgas Telekomunikasi Nusantara palembang.

Beberapa penelitian pernah dilakukan mengenai sistem persediaan (inventory), antara lain penelitian dari kasus yang sama yaitu Pengembangan sistem informasi ketersediaan barang oleh Syarif Hidayatullah universitas islam negeri Jakarta. Syarif hidayatullah melakukan penelitian di perusahaan perdagangan komoditas hasil bumi nusantara. Sementara penulis melakukan penelitian di perusahaan telekomunikasi. Syarif lebih menekankan penggunaan sistem informasi untuk meningkatkan layanan persediaan barang yang akan dijual atau dipasarkan. Sementara penulis merancang sistem informasi ketersediaan barang untuk proses dalam pelayanan pelanggan, sehingga memudahkan dalam memonitor persediaan barang/ Spare part, sehingga karyawan/teknisi PT.PGAS Telekomunikasi Nusantara Palembang dalam melaksanakan pelayanan bisa memberikan hasil yang tepat dan cepat dengan stok yang tersedia.

Penelitian lainnya yaitu analisis sistem informasi manajemen persediaan barang berupa modem internet dan modem televisi (Studi kasus pada PT. Telekomunikasi Indonesia, Tbk) Bandung. Penelitian ini dilakukan hanya sebatas menganalisis sistem informasi manajemen persediaan barang seperti modem internet dan modem televisi untuk melihat fungsi dari sistem informasi bagi peningkatan kinerja Perusahaan dan realisasi produk perusahaan kepada konsumen dalam bentuk jasa.

Penelitian selanjutnya yaitu analisis sistem pengendalian persediaan barang dagang pada PT.Sungai budi di Palembang, penelitian ini bertujuan untuk mengetahui tentang sistem pengendalian persediaan barang, prosedur pemesanan, penerimaan dan pengeluaran barang pada PT.Sungai budi di Palembang sudah memadai. Sehingga dapat menghindari adanya kekurangan stok (stock out) maupun kelebihan atau penumpukan stok barang dagang.

\section{Metodologi}

Alur penelitian merupakan urutan langkah-langkah kerja dalam melakukan penelitian agar penulisan lebih terarah dalam penyelesaian masalah yang dibahas. Adapun tahapan alur penelitian dapat dilihat pada gambar di bawah ini : 


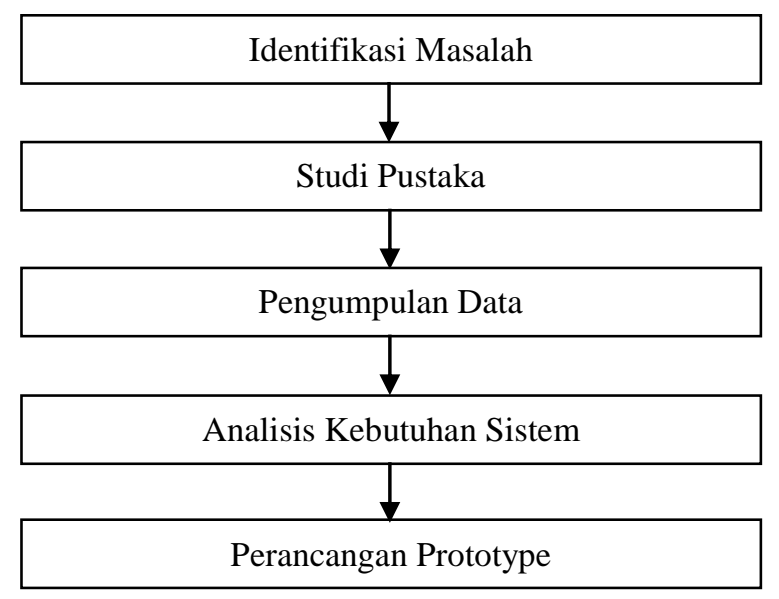

Gambar 1 Alur Penelitian

Berdasarakan alur penelitian yang telah digambarkan pada gambar 1 maka dapat diuraikan pembahasan masing-masing tahap pada alur penelitian yang penulis lakukan adalah sebagai berikut :

1. Identifikasi Masalah

Secara teknis pengiriman dan pencatatan laporan inventory yang saat ini dilakukan oleh PT.Pgas Telekomunikasi nusantara Palembang tidak memiliki kendala yang signifikan. Namun demikian pengembangan kinerja tentu saja menjadi prioritas agar kegiantan pencatatan ataupun laporan gudang bisa dilakukan tidak dengan proses manual saja tetapi dapat dilakukan melalui sebuat sistem. Dengan adanya sistem tersebut akan memberikan dampak positif bagi perusahaan karena akan mengurangi biaya pengiriman laporan fisik dan juga data yang akurat dapat diketahui secara cepat dan tepat.

2. Studi Pustaka

Pada tahap ini penulis akan mempelajari buku-buku referensi, artikel pada situs-situs yang relevan dan hasil penelitian sejenis sebelumnya yang pernah dilakukan orang lain. Tujuannya adalah untuk mendapatkan landasan teori mengenai masalah yang akan diteliti pada PT.Pgas Telekomunikasi Nusantara Palembang. Teori ini merupakan pijakan bagi penulis untuk memahami persoalan yang diteliti dengan benar sesuai dengan kerangka berpikir ilmiah.

3. Pengumpulan Data

Pengumpulan data dilakukan dengan mencari informasi yang berkaitan dengan masalah yang diteliti, yang berasal dari dokumen-dokumen PT.Pgas Telekomunikasi Nusantara Palembang atau melalui observasi dan wawancara dengan pihak terkait.

a. Data Primer

Data primer yaitu data yang diperoleh secara langsung. Data ini diperoleh dari hasil wawancara dengan pihak terkait yang dijadikan sampel dalam penelitian. Data dapat direkam atau dicatat oleh peneliti. Berikut adalah metode pengumpulan yang digunakan penulis :

1) Wawancara

Yaitu teknik pengumpulan data dengan melakukan tanya jawab dengan karyawan pada bagian yang berhubungan dengan masalah yang diambil oleh penulis.

2) Observasi

Observasi merupakan salah satu metode pengumpulan data dengan langsung terjun kelapangan untuk mengamati permasalahan sistem yang ada di PT.Pgas Telekomunikasi Nusantara Palembang.

b. Data Sekunder

Data -data yang diperoleh dari buku literatur, internet, dan media lain yang berhubungan dengan topik penelitian.

4. Analisis Kebutuhan Sistem

Tahapan analisis sistem dimulai karena adanya permintaan terhadap sistem baru. Bisa juga karena diinginkannya pengembangan dari sistem yang sedang berjalan. Permintaan dapat datang dari seorang manajer di luar departemen sistem informasi atau dari pihak eksekutif yang melihat adanya masalah atau menemukan adanya peluang baru. Pada bagian ini Peneliti menguraikan mengenai gambaran atau profil 
perusahaan serta uraian mengenai sistem yang sedang berjalan saat ini. Pada bagian ini Peneliti juga akan menjabarkan mengenai permasalahan pada sistem yang sedang berjalan dan analisa sistem yang diusulkan.

5. Perancangan Prototype

Dalam perancangan sistem ini, penulis juga menggunakan UML (Unified Modelling Language) sebagai tools untuk perancangan dan pengembangan aplikasinya. UML mempunyai sejumlah elemen grafis yang bisa dikombinasikan menjadi diagram. Karena ini merupakan sebuah bahasa,UML memiliki sejumlah aturan untuk menggabungkan/mengkombinasikan elemen-elemen tersebut.

\section{Hasil dan Pembahasan}

\subsection{Analisis Sistem yang berjalan}

Sesuai dengan data dan informasi yang peneliti dapatkan selama melakukan penelitian pada PT. Pgas Telekomunikasi Nusantara Palembang. Maka peneliti dapat merumuskan sistem berjalan pada bagian teknis adalah sebagai berikut:

Kantor management PT. Pgas Telekomunikasi Nusantara Palembang memiliki gudang yang terpisah sehingga untuk melakukan kegiatan bisnisnya memerlukan waktu untuk perjalanan dari gudang ke kantor. Pada PT. Pgas Telekomunikasi Nusantara Palembang memiliki beberapa bagian, diantaranya bagian teknis, pemasaran dan bagian keuangan. System inventory ini ditekankan untuk bagian teknis. Bagian teknis pada PT. Pgas Telekomunikasi Nusantara Palembang adalah bagian yang mengolah barang, mengatur persediaan barang, memberikan laporan kondisi produk/perangkat dan pasokannya secara berkala kepada direktur utama. Bagian teknis menerima form request yang dilakukan oleh direktur utama untuk memesan barang sehingga sudah siap untuk dikirim. Bagian teknis barang tidak melakukan pemesanan apabila tidak adanya form Permintaan Barang (Work Order) yang diajukan oleh direktur utama.

Pada sistem yang berjalan saat ini, semua User melakukan perintah kerja dan segala kegiatan pelaporan dilakukan dengan manual. Sebagai contoh, dapat peneliti berikan gambaran alur yang biasa terjadi dalam keseharian proses bisnis yang terjadi pada PT. Pgas Telekomunikasi Nusantara Palembang, sebagai berikut:

1. Admin gudang menerima barang masuk dari Supplier dan kemudian mencatatnya.

2. Admin gudang menerima Permintaan Barang (Work Order) dari direktur teknis untuk penggunaan barang.

3. Admin gudang membuat laporan penggunaan barang.

4. Direktur utama menerima laporan secara berkala dari semua Penggunaan barang.

5. Direktur teknis melihat ketersediaan barang sebelum membuat Permintaan Barang (Work Order) untuk dikerjakan oleh bagian teknis.

Gambaran di atas adalah gambaran keseharian yang terlihat pada PT. Pgas telekomunikasi Nusantara Palembang dalam melakukan perintah pemakaian barang, pencatatan Penggunaan Barang masih menggunakan lembaran kertas yang kemudian dipindahkan ke dalam komputer melalui program MS. Excel dan masih stand alone sehingga tidak bisa diakses oleh manager secara langsung.

Sesuai dengan analisa yang peneliti lakukan, peneliti mendapatkan permasalahan yang sering terjadi pada sistem berjalan, yaitu :

1. Pencatatan masih dalam lebaran kertas kemudian dipindahkan ke dalam komputer serta masih stand alone.

2. Kebutuhan karyawan atas pelayanan yang memerlukan proses cepat dan tepat.

3. Pengolahan laporan berkala untuk direktur utama masih terbatas karena tidak dapat dilakukan sewaktu-waktu.

\subsection{Analisis Sistem Usulan}

Setelah melihat data maupun informasi yang dibutuhkan dan melihat sistem berjalan pada PT.Pgas telekomunikasi nusantara palembang sepintas tidak memiliki kendala yang bearti, namun bila melihat langsung pada prakteknya di lapangan sistem yang berjalan memiliki kendala. Yaitu dalam hal sistem aplikasi pengolahan barang di gudang dimana di dalamnya mengenai penyimpanan data barang, penyimpanan data Supplier, penyimpanan data persediaan barang, Input data barang masuk, transaksi-transaksi, hingga tahap laporan. Dalam hal ini suatu pengolahan data pada perusahaan tersebut sangat membutuhkan aplikasi yang dapat menjadi solusi dari kendala-kendala 
tentunya dapat memudahkan kinerja karyawan sehingga kegiatan perusahaan dapat berjalan efektif, lancar dan efisien.

Pada Sistem yang akan diusulkan terdapat 3 pengguna sistem, yaitu: User dir_utama yang memiliki akses pada sistem ini hanya untuk melihat laporan-laporan data barang masuk dan keluar, data Supplier, data pelanggan dan laporan data ready stock yang tersedia digudang. Yang kedua ialah User adm_gudang yang memiliki hak ases untuk sistem ini antra lain untuk mengInput data-data barang masuk dan keluar, data Supplier, data pelanggan dan mengInput data sortir barang yang dilakukannya. Ketiga, User front_desk yang memiliki hak ases pada sistem ini hanya untuk mengecek ketersediaan barang didalam gudang

Pada tahapan ini, peneliti menggunakan metode SDLC ( System Development Life Cycle) dan Unified Modelling Language (UML) sebagai tools untuk menvisualisasikan sistem yang sedang berjalan.

\subsection{Perancangan Prototype}

Sebuah Prototype dipersiapkan untuk setiap antarmuka sistem sebagai gambaran bagaimana suatu sistem terlihat oleh User dan programmer. Berdasarkan rancangan sistem yang telah diuraikan sebelumnya, maka perlu disajikan Prototype. Adapun penyajiannya diuraikan berdasarkan subsistem sebagai berikut :

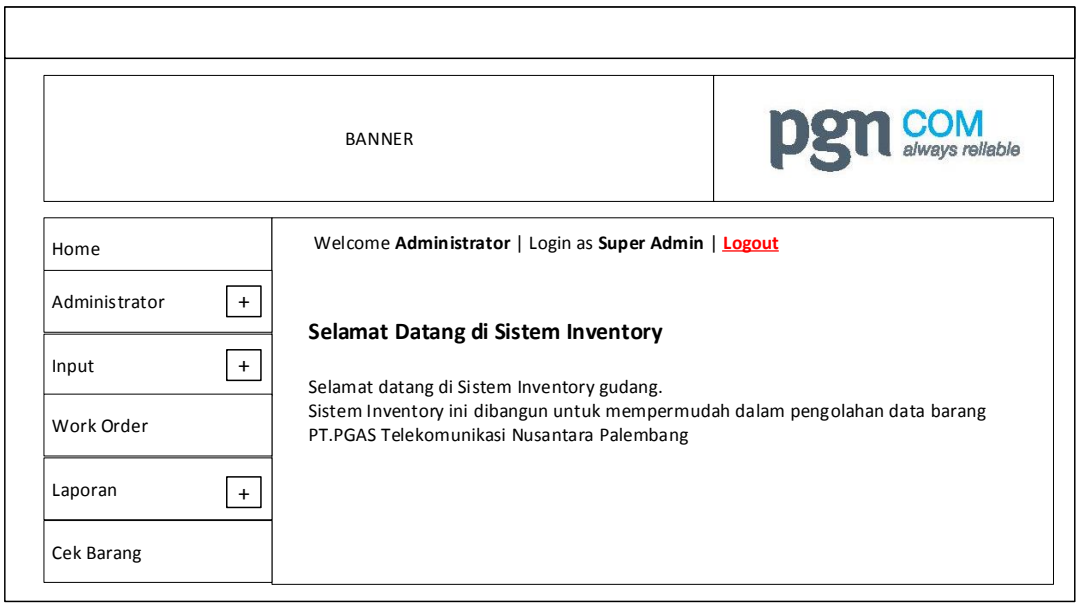

Gambar 2 Prototype Tampilan Menu Utama

\subsubsection{Prototype Input}

4.3.1.1 Prototype Input Data Barang Masuk

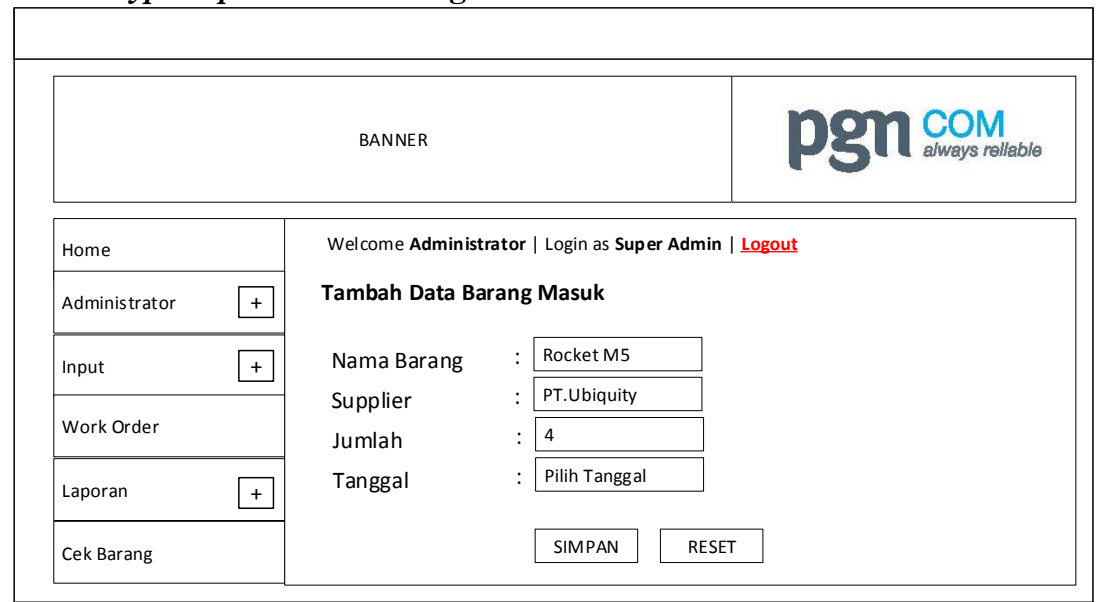

Gambar 3 Prototype Input Data Barang Masuk 


\subsubsection{Prototype Input Data Barang Keluar}

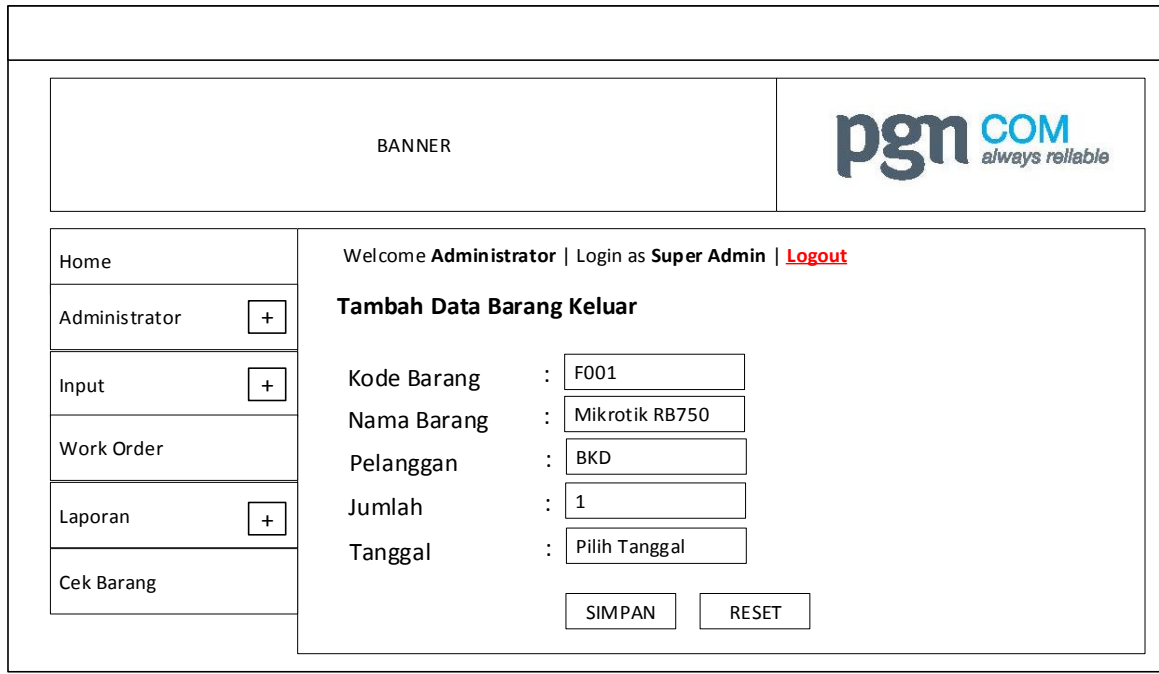

Gambar 4 Prototype Input Data Barang Keluar

\subsubsection{Prototype Input Data Supplier}

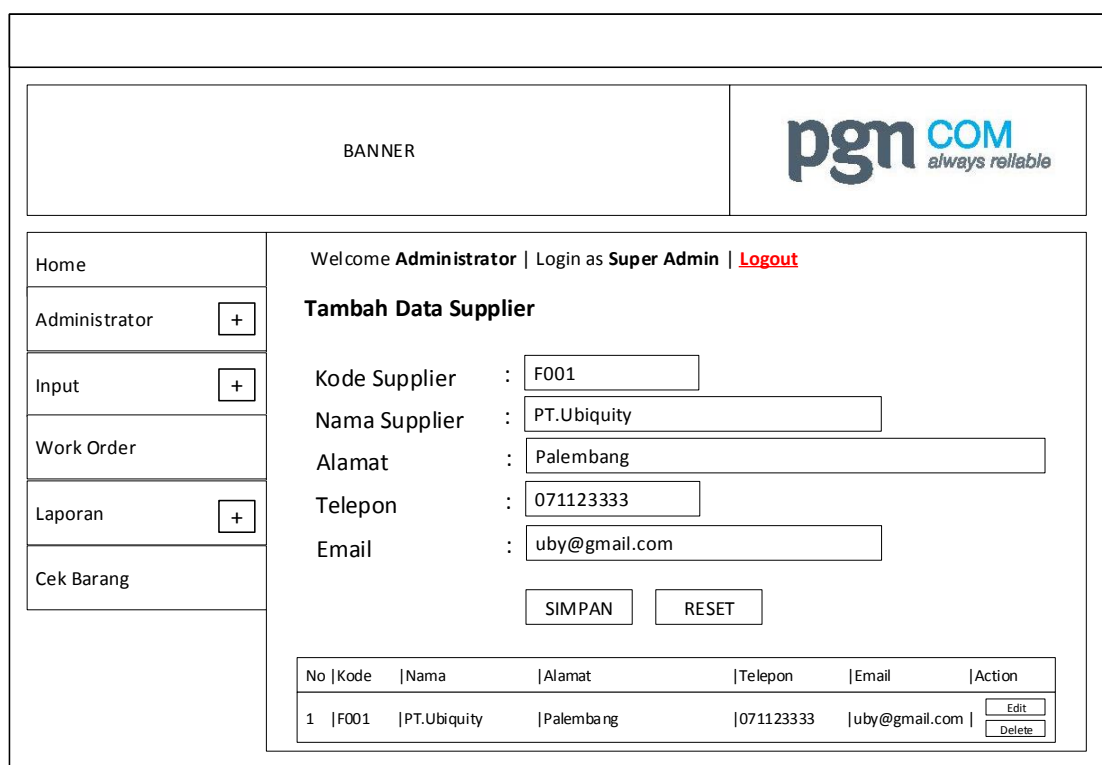

Gambar 5 Prototype Input Data Supplier 


\subsubsection{Prototype Input Data Pelanggan}

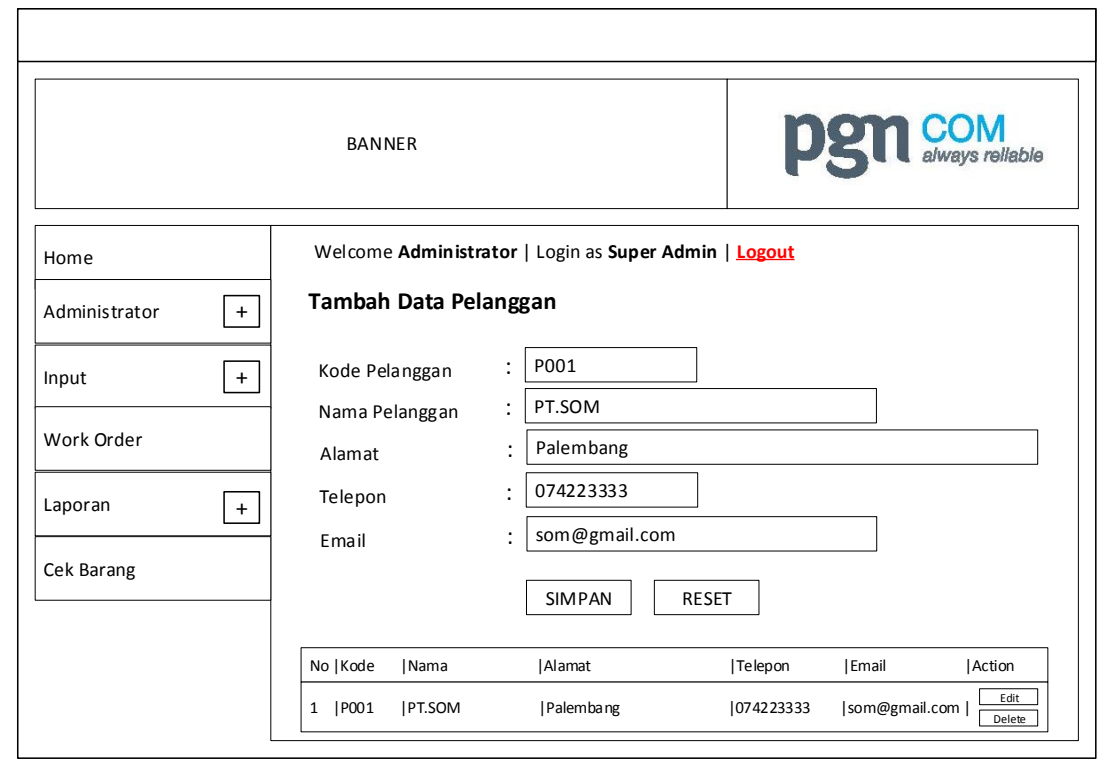

Gambar 6 Prototype Input Data Pelanggan

\subsubsection{Prototype Input Data Sortir}

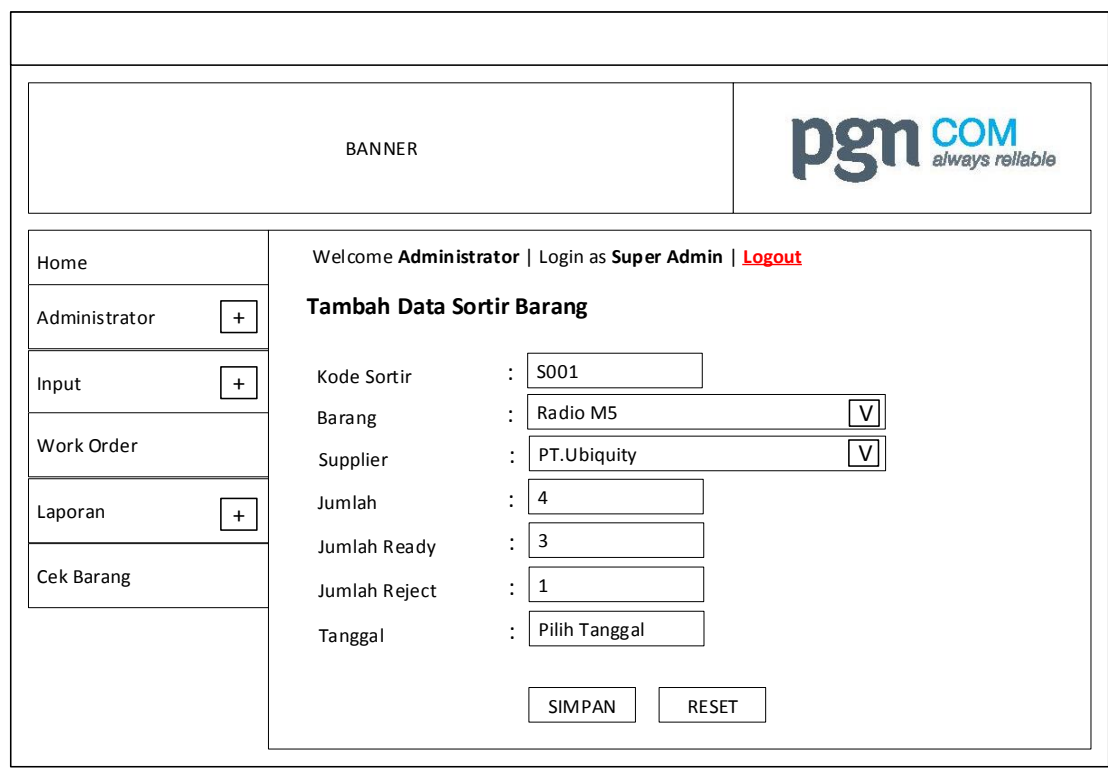

Gambar 7 Prototype Input Data Sortir 


\subsubsection{Prototype Input Data Permintaan Barang}

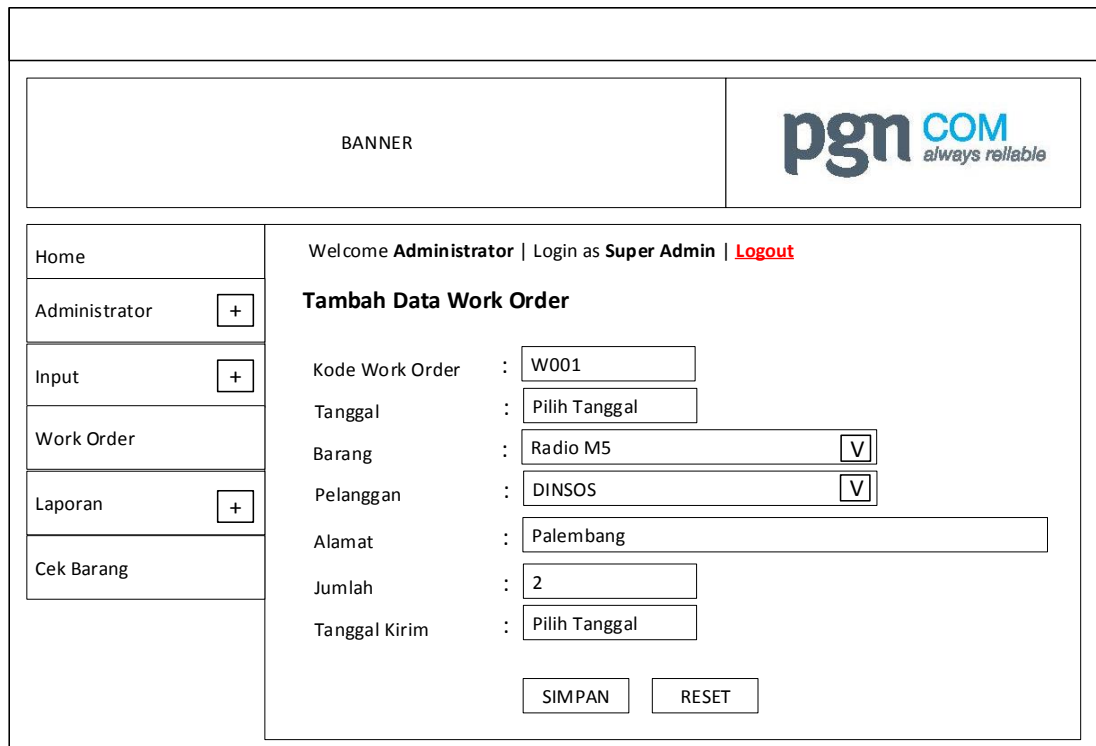

Gambar 8 Prototype Input Permintaan Barang

\subsubsection{Prototype Laporan}

Interface adalah sebuah media yang menghubungkan antara pengguna (User) dengan sistem. Sistem yang akan dibangun diharapkan dapat menyediakan interface yang mudah dipahami oleh pengguna, jika interface dibuat terlalu rumit akan memakan waktu bagi pengguna untuk memahami dan menggunakannya.

\subsubsection{Prototype Laporan Data Barang Masuk}

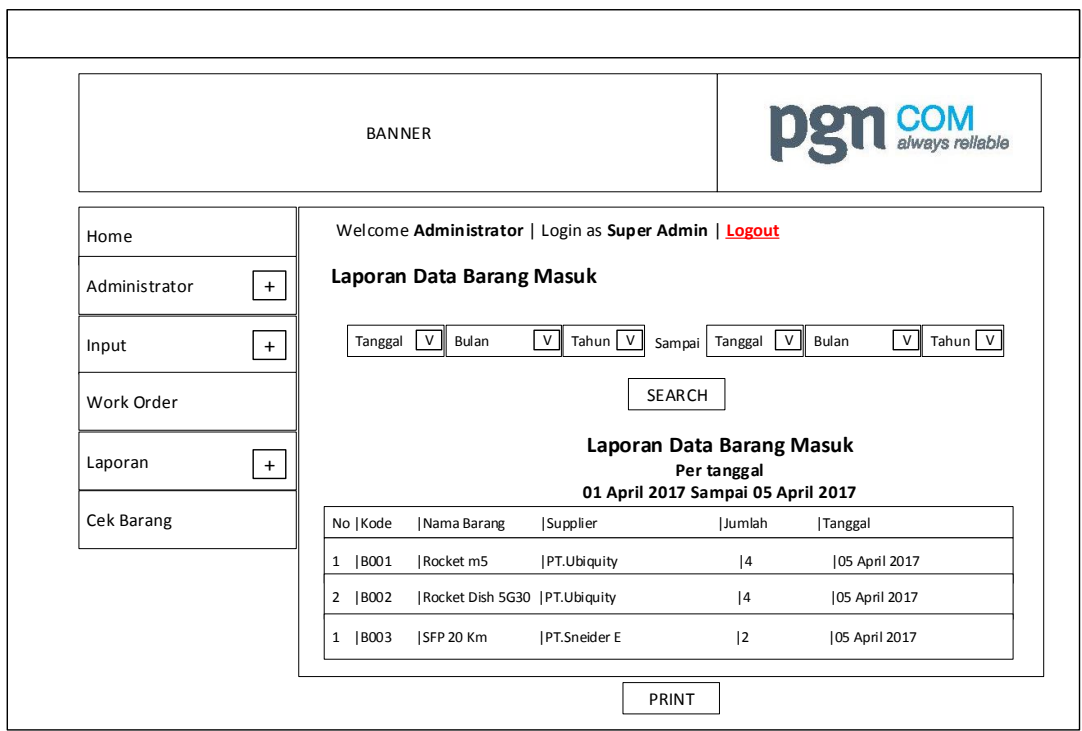

Gambar 9 Prototype Laporan Data Barang Masuk 


\subsubsection{Prototype Laporan Data Barang Keluar}

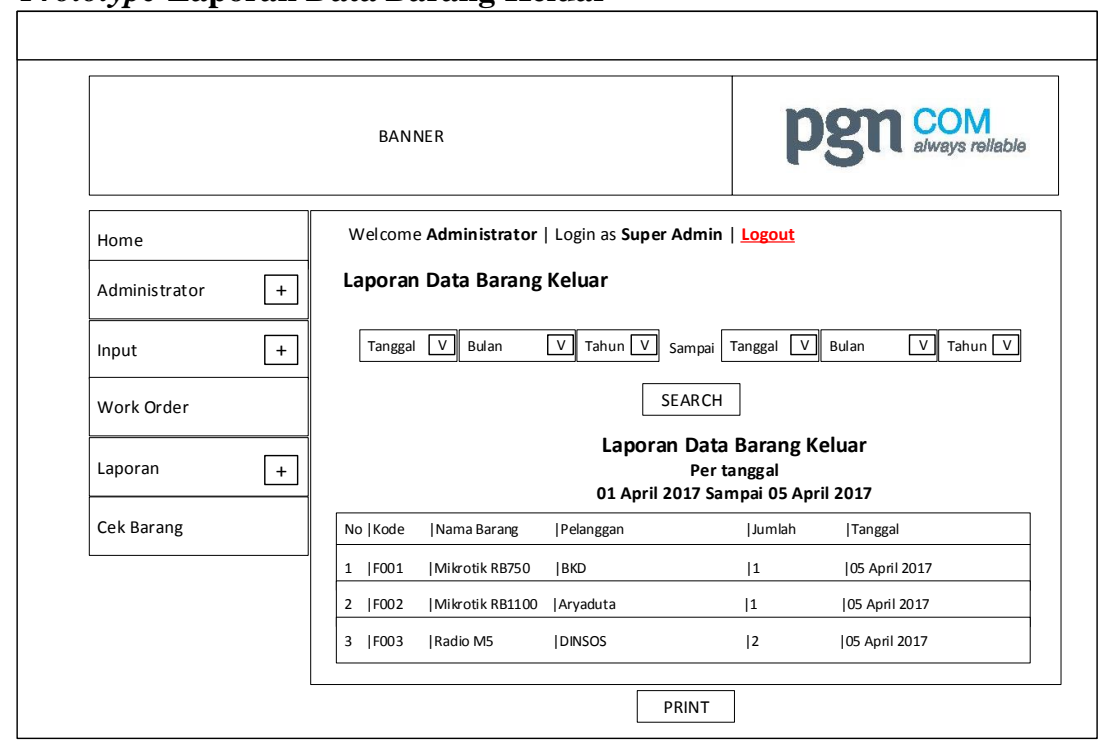

Gambar 10 Prototype Laporan Data Barang Keluar

\subsubsection{Prototype Laporan Data Supplier}

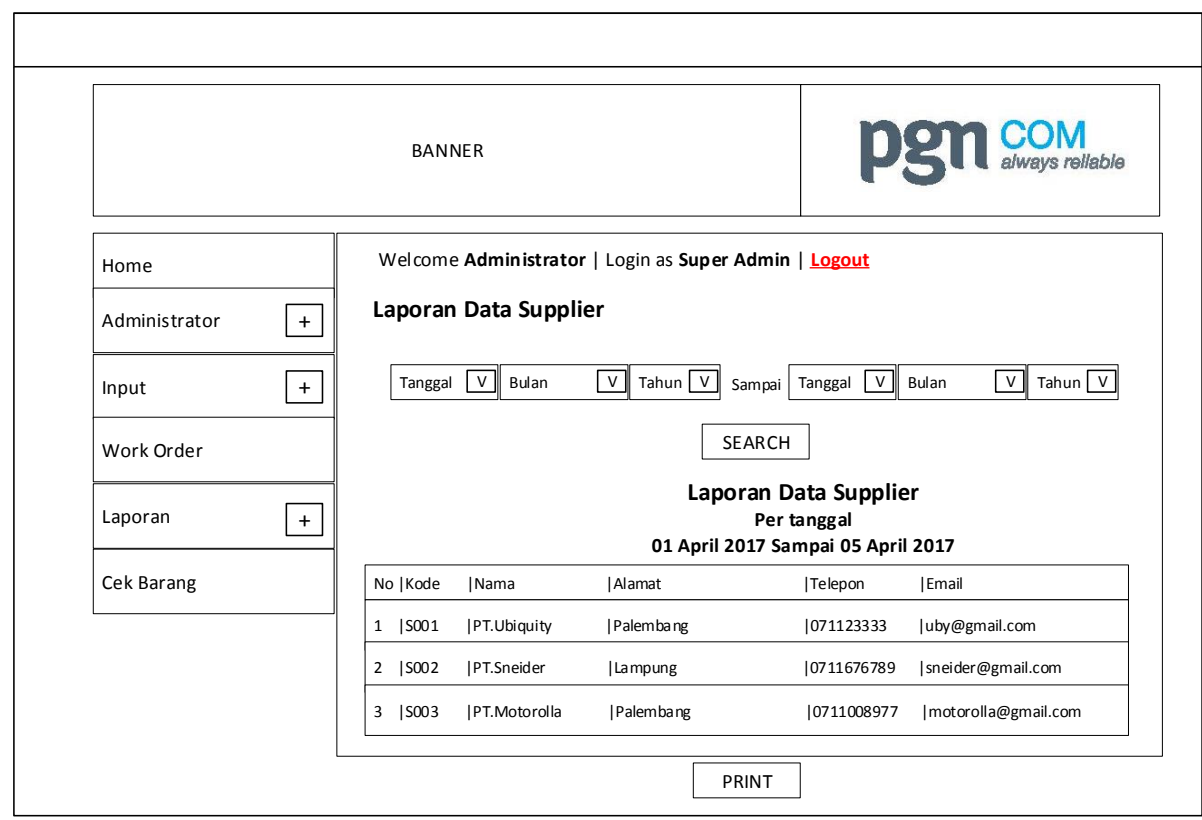

Gambar 11 Prototype Laporan Data Supplier 


\subsubsection{Prototype Laporan Data Pelanggan}

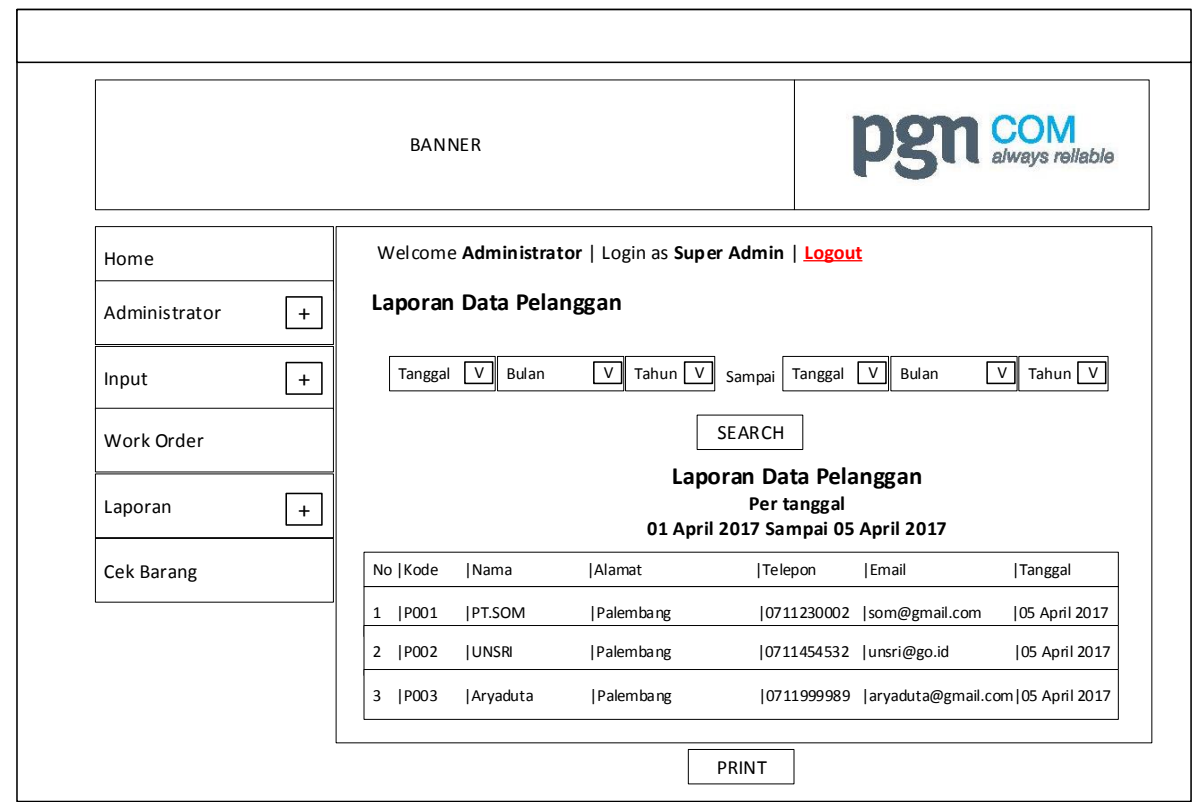

Gambar 12 Prototype Laporan Data Pelanggan

\subsubsection{Prototype Laporan Data Sortir}

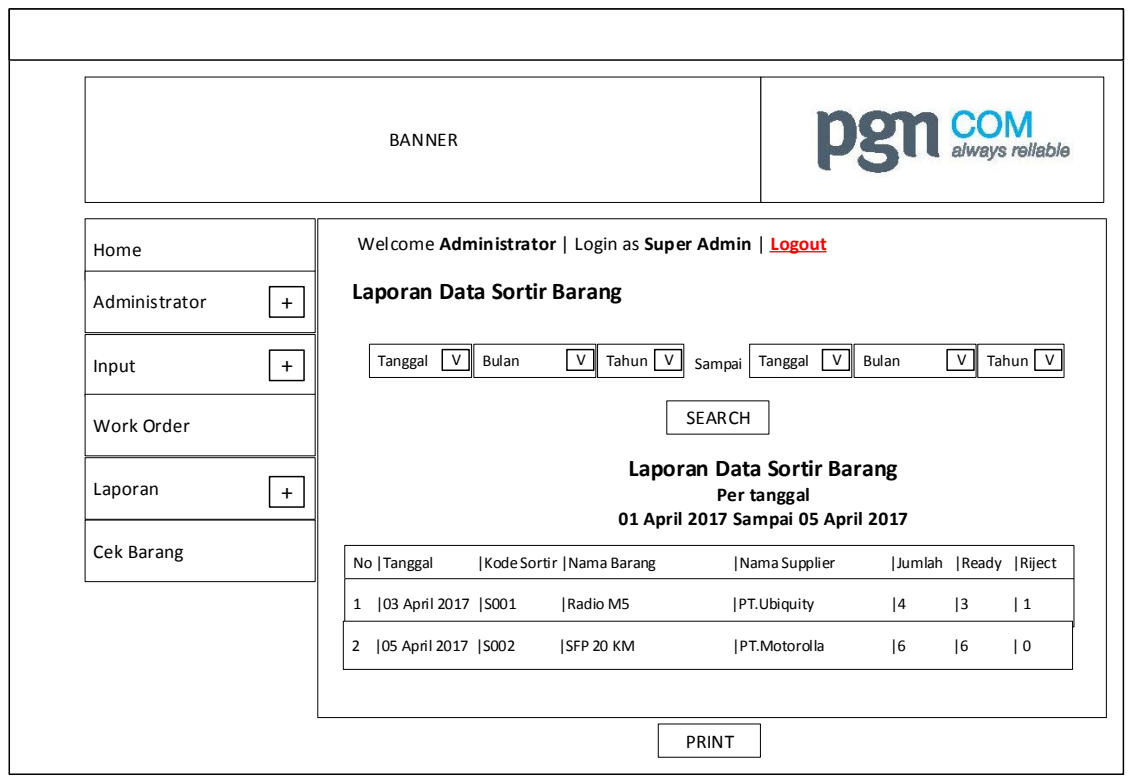

Gambar 13 Prototype Laporan Data Sortir 


\subsubsection{Prototype Laporan Data Permintaan Barang}

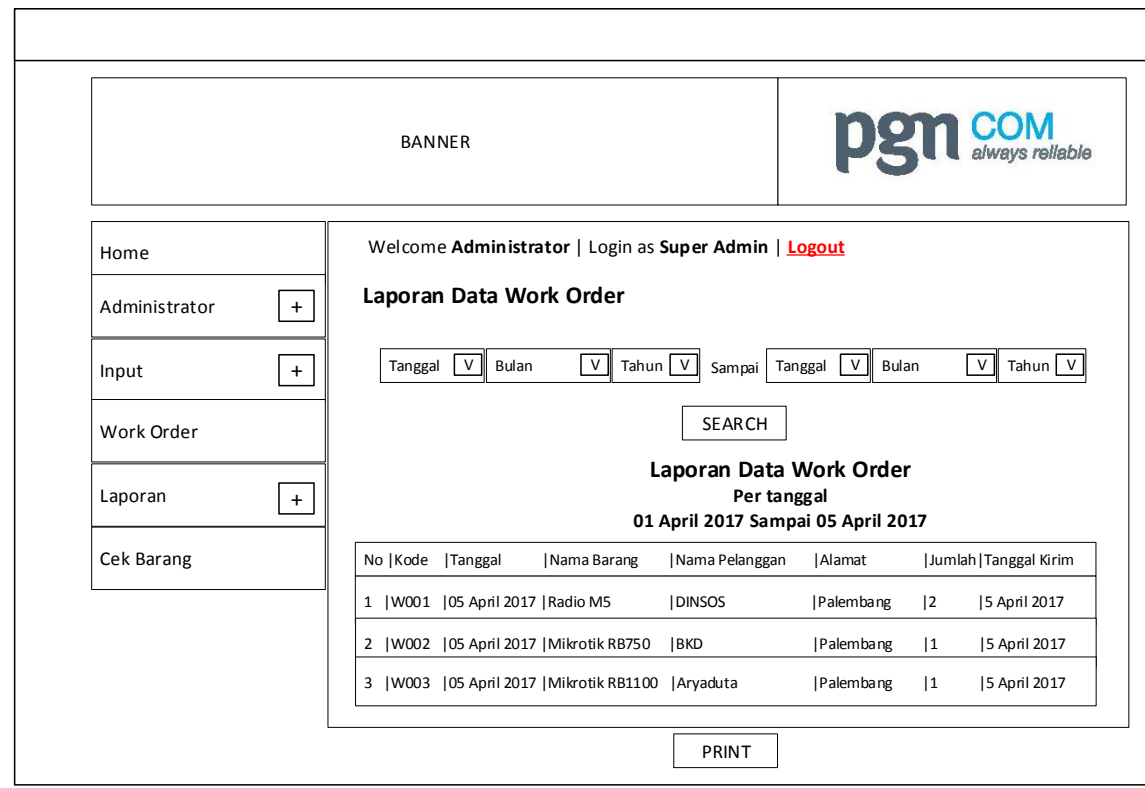

Gambar 14 Prototype Laporan Permintaan Barang

\subsubsection{Prototype Laporan Ready Stock}

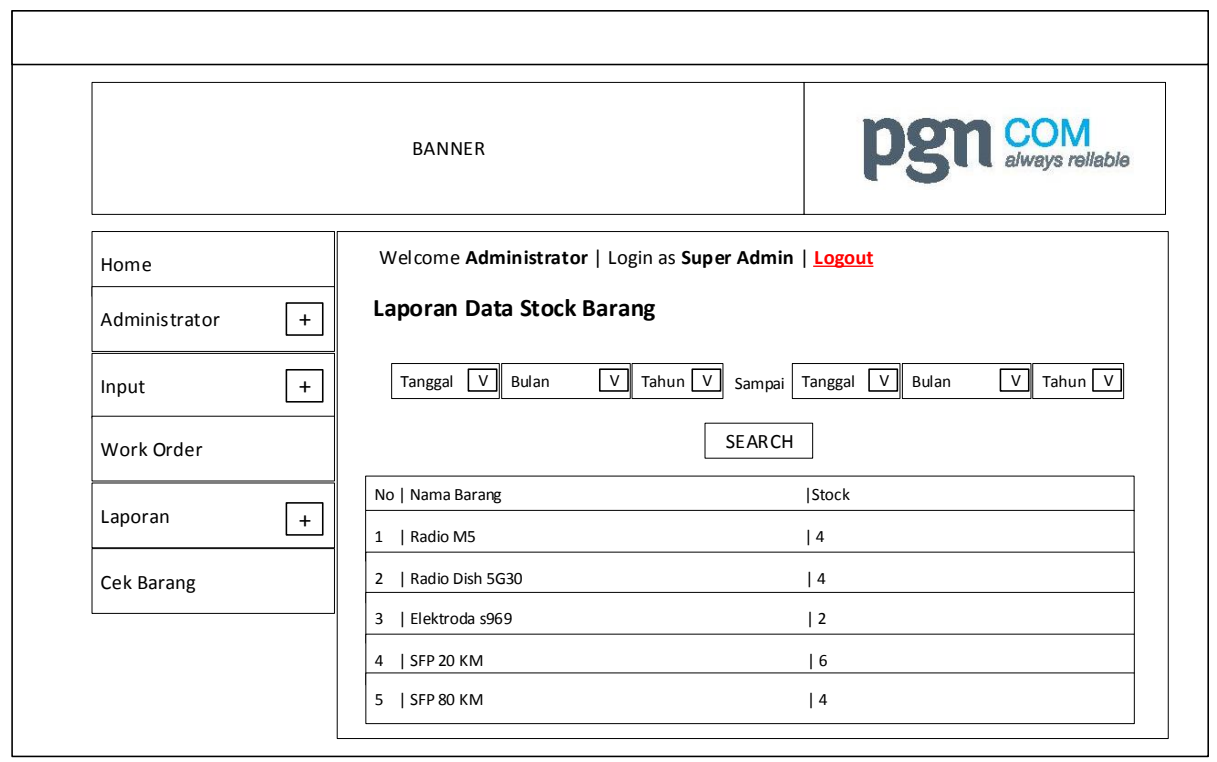

Gambar 15 Prototype Laporan Ready Stock

\section{Kesimpulan}

Berdasarkan analisis dan perancangan sistem yang telah dilakukan penulis, berikut adalah simpulan dan saran untuk penelitian ini.

\subsection{Simpulan}

Berdasarkan Dari akhir penelitian yang dilakukan dalam PT.PGAS Telekomunikasi Nusantara Palembang ini maka didapat beberapa kesimpulan : 
1. Penelitian ini menghasilkan prototype Inventory. yang bertujuan agar perusahaan PT. Pgas Telekomunikasi Nusantara Palembang dapat melakukan pengembangan gudang dan persediaan barang secara cepat sehingga sesuai kebutuhan perusahaan.

2. Sistem yang dirancang menggunakan 3 user sebagai pengguna utama sistem ini sehingga memudahkan dalam pengolahan data yang cepat dan akurat.

3. Untuk Memperluas dan Meningkatkan angka layanan terhadap pelanggan khususnya produk layanan internet PT.PGAS Telekomunikasi Nusantara Palembang.

\subsection{Saran}

Sebuah penelitian yang baik adalah bagaimana penelitian itu dapat dipahami oleh pembaca dan hasil penelitiannya dapat dikembangkan sehingga menjadi lebih baik, hasil penelitian yang dilakukan ini belum dapat dikatakan baik dan jauh dari sempurna, untuk itu perlu masukan dari berbagai pihak. Berdasarkan simpulan-simpulan yang telah dikemukakan, dapat diajukan beberapa saran untuk pengembangan lebih lanjut untuk manajemen perusahaan dan peneliti selanjutnya, antara lain :

1. Pada tahap pelaporan agar dikembangkan menjadi bentuk grafik, agar tampilan lebih terlihat menarik tidak hanya dalam bentuk tulisan saja.

2. Pengembangan sistem inventory ini dapat dikembangkan ke bagian pembayaran dan distribusi.

3. Dalam penggunaan sistem ini membutuhkan user yang terampil, untuk itu penting untuk diberikan pelatihan pengoperasian maupun pemeliharaan software dari kerusakan sistem.

\section{Daftar Rujukan}

[1] Agus, Ristono. 2009 . Manajemen Persediaan. Graha Ilmu. Yogyakarta

[2] Febrian, Jack. 2004. Pengetahuan Komputer dan Teknologi Informasi. Bandung : Informatika.

[3] Fowler, Martin. 2005. UML Disttilled. Edisi ketiga. Yogyakarta : Andi.

[4] Hermawan, Julius. 2004. Analisa Design dan pemrograman Berorientasi Objek dengan UML dan Visual Basic.Net. ANDI. Yogyakarta.

[5] Hartono, Jogianto. 2013. Sistem Teknologi Informasi. Salemba Empat. Jakarta

[6] James A, O’Brien. 2005. Introdution to Information System, Terjemahan oleh Dewi Fitriasari, Jakarta : Salemba Empat.

[7] Kendall E Kenneth dan Kendall E Julie, 2006. Analisis dan Perancangan Sistem. Edisi keempat.Bandung : PT Indeks.

[8] Mcleod, Raymond dan Schell, George. 2004. Sistem Informasi Manajemen. Jakarta : PT.Index.

[9] Munawar. 2005. Pemodelan Visual dengan UML. Edisi Pertama. Graha Ilmu. Yogyakarta

[10] Raharjo, Budi. 2011. Belajar Otodidak Membuat Database Menggunakan MySQL. Informatika. Bandung

[11] Rangkuti Freddy. 2004. Manajemen Persediaan. PT.RajaGrafindo Persada. Jakarta

[12] Siagian, Yolanda M. 2005. Aplikasi Supply Chain Management dalam Dunia Bisnis. PT Grasindo. Jakarta

[13] Nasution, A.H; dan Prasetyawan, Y. 2008. Perencanaan dan Pengendalian Produksi, Edisi Pertama. Graha Ilmu. Yogyakarta

[14] Ma'arif Syamsul; dan Hendri Tanjung, 2003. Manajemen Operasi, Edisi Pertama, PT.Grasindo. Jakarta

[15] Harjanto, Eddy. 2008. Manajemen Operasi, Edisi ke-3, Grasindo. Jakarta.

[16] Sutabri, Tata. 2004. Analisa Sistem Informasi. ANDI. Yogyakarta.

[17] Yogianto, H.M. 2005. Analisis dan Desain : Sistem informasi pendekatan Terstruktur teori \& Praktek aplikasi Bisnis. ANDI. Yogyakarta. 